\title{
Research on the Interestingness of Graphic Design of Public Service Advertisements
}

\author{
Yang Xin \\ Liaoning Institute of Science and Technology, Liaoning, China
}

Keywords: public service advertisement; fun; expression

\begin{abstract}
With the rapid development of China's advertising industry, the type of advertising presents a colorful situation. Public service advertisements are unique among many types of advertisements due to their particularity of theme, creativity and performance. Public service advertisements have a positive effect on the dissemination of moral concepts and the creation of a civilized atmosphere, and are increasingly becoming an important carrier for the creation of spiritual civilization and the construction of civic morality. Interestingness is widely used in print advertising design, and advertising designers attract the attention of advertising audiences through graphic or linguistic interest. Therefore, it is very important to apply interestingness in the graphic design of public service advertisements. This paper briefly introduces the psychological effects of interest in the graphic design of public service advertisements, and mainly studies the expressions of "intesrestingness" in the graphic design of public service advertisements in order to strengthen the construction of public service advertisements.
\end{abstract}

\section{Introduction}

In modern society, print ads are filled with every corner of society. These advertisements are mediocre, while others are unique, novel and pleasant, which impress people. The reason for this difference is that, in addition to the technical level of production, the level of advertising creativity is also an extremely important reason, and the most important thing is whether advertising is interesting. An interesting advertisement can draw people's attention, give a deep impression, break the secular view, and change people's perception of a certain product or thing ${ }^{[1]}$.

2. The psychological effect of the interest in the graphic design of public service advertisements

\subsection{Interesting and attention}

With the development of the economy and the development of society, people have more and more advertisements in their lives. Only a small part of the many advertisements people encounter have been noticed by people. After investigation, the average number of advertisements people encounter every day. About 150, and the average person who is really concerned about is only about 15. The purpose of advertising is to attract people's attention, which is the eyeball economy. 
Therefore, only the advertisement wood that is noticed can be regarded as a successful advertisement, and the advertisements are used to stimulate people's desires and needs to achieve the purpose of advertisement. In order to increase people's attention to advertising, it can increase the interest of advertisements, attract people's balls through interesting advertisements, and let people be interested in advertisements to pay attention to advertisements. In order to increase the interest of advertising, when advertising design increases interest, new heterosexuality and irritability must be incorporated into interesting design. Advertising with these two conditions is more concerned, making advertising more effective. As shown in Figure 1, this kind of advertising can attract more people's attention.

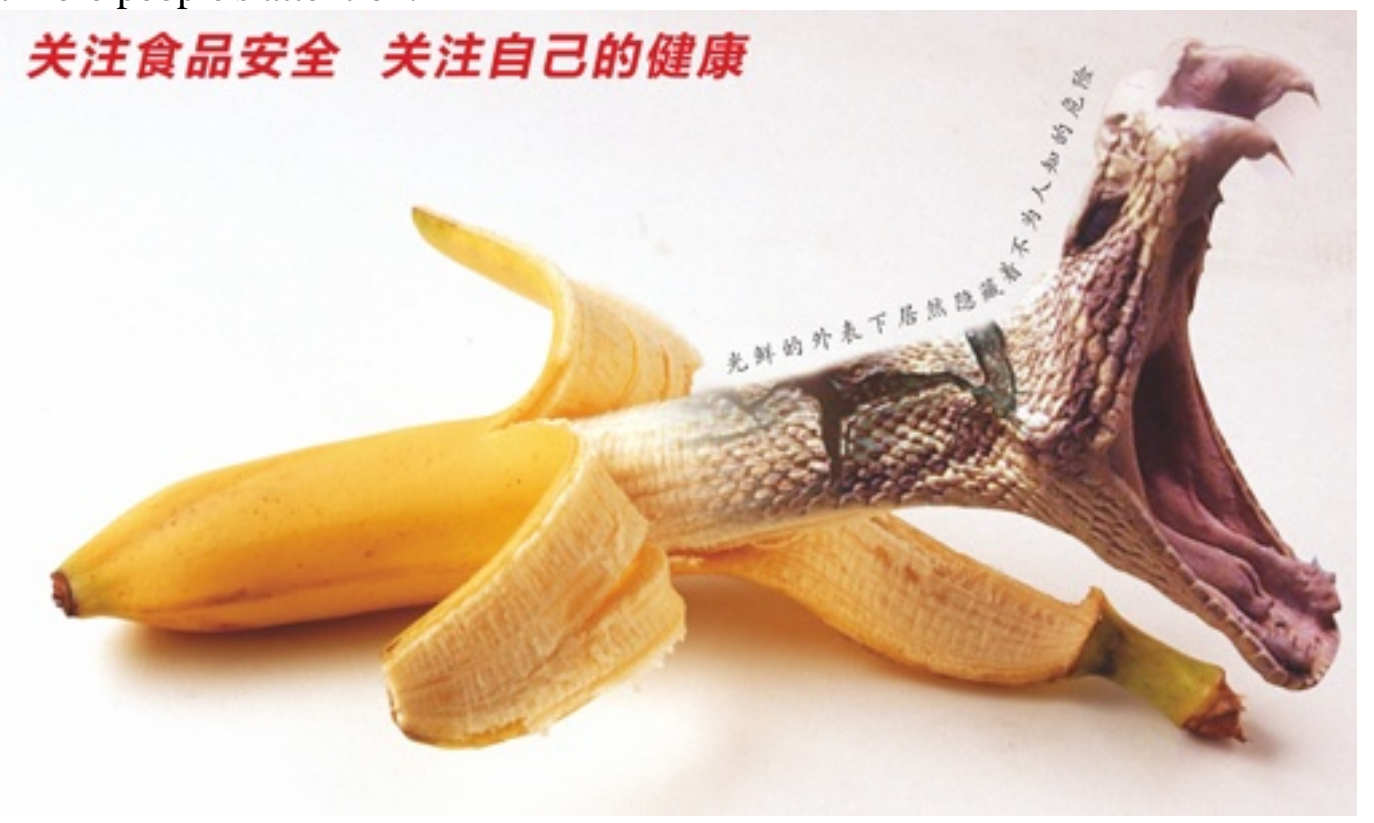

Figure 1 Food safety public service advertisement

\subsection{Interesting and needs}

Advertising has now entered a stage of rapid development. Advertisements can be seen everywhere in streets and in life. Therefore, the reason why advertising develops so rapidly is the most important reason for demand. Advertising usually acts as a bridge to build a bridge between products and people, making products better circulated. Advertising companies and advertisers benefit from the accepted population, so people must benefit from advertising and provide some kind of demand for the advertising audience, so that the advertising audience will pay attention to the content of the advertising. Advertising is now one of the main ways people get useful information, so advertising content must reflect a certain need to meet the needs of the advertising audience. Therefore, when designing the public service advertisement graphic, it is interesting to show a certain meaning, so that when people are attracted by advertising interest and pay attention to the advertisement, they can get what they need from the advertisement ${ }^{[2]}$.

\subsection{Fun and association and imagination}

Association is the mental process of thinking about something in the past or in the future. Thus modern advertising design will often law is blended in among them, association and imagination to achieve the effect of increasing interest, using the law of association and imagination, people are paying attention to the advertisement is easily affected by interest, for the content of the 
advertisement or imagination, imagination expressed by the contents of the advertisements content, naturally into the advertising of artistic conception, from will increase with the advertising audience's memory, when the future one day need the things in the advertising, will naturally think of advertising. Imagination is a sublimation based on association. Imagination is not the association of things in the past, but the imagination of things in the perception, creating new things in the brain. The content of imagination contains many kinds. The imaginary can be either past, present or future. Even the imaginary can be nonexistent or formed. Although the artistic creation of advertisement design is based on the things in the real society, the imagination can not be limited to the real things, so as to give more space for the audience to imagine, increase the interest and effect of the advertisement, and achieve the purpose of the advertisement ${ }^{[3]}$.

\section{The performance of "fun" in the graphic design of public service advertisements}

The "fun" of graphic design is a state of psychological reaction in a visual sense. The expression of "fun" in art design is mainly reflected in the visual aspect, including the application of graphic creativity and form surprise.

\section{1 "Fun" in graphic creativity}

Graphics are information carriers that are easily remembered and recognized, and can effectively spread information across language barriers between countries and nations. One of the most important features of graphic creativity is the abnormality, consciously destroying, creating contradictions and conflicts, breaking up and refactoring, allowing the viewers to brighten their eyes and achieve attractive goals, so as to better convey information.

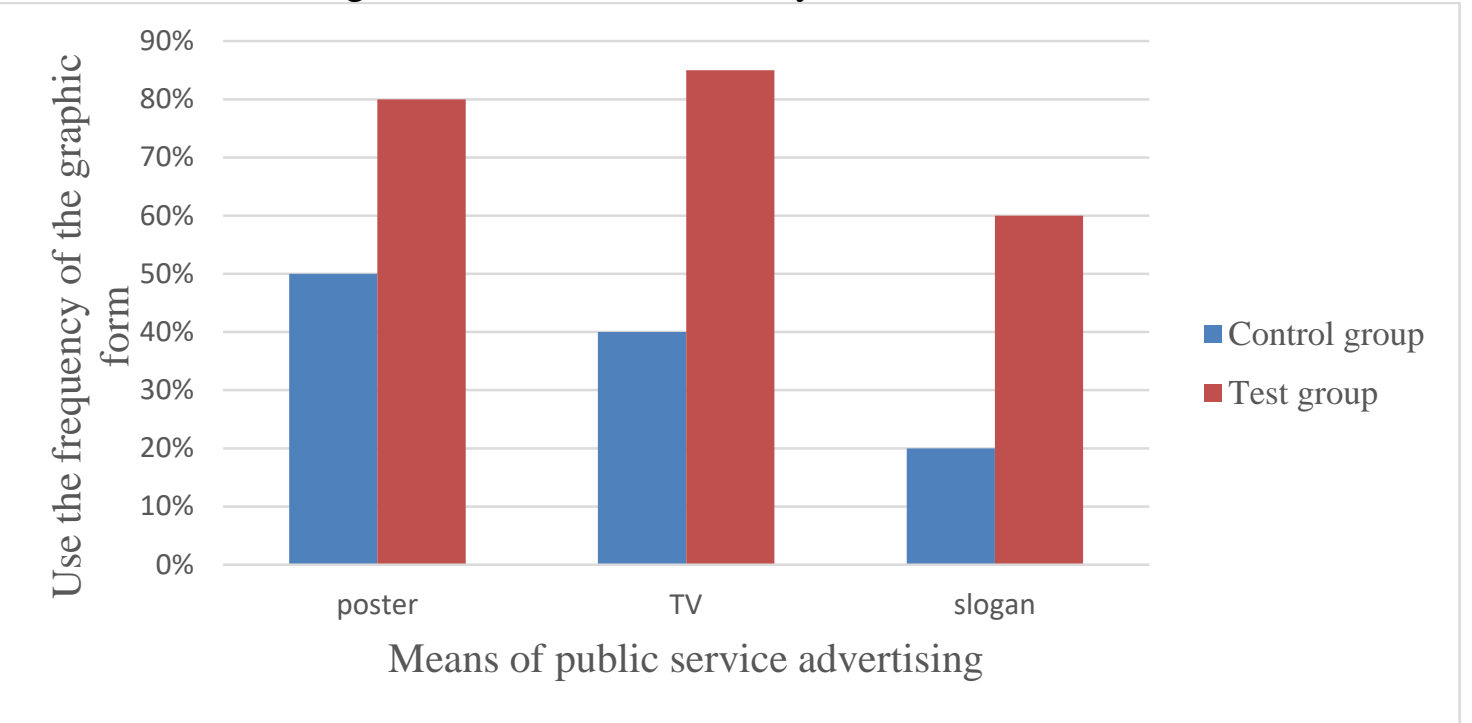

Figure 2 The development trend of graphic creative public service advertisement

The final appearance of graphic creativity is an interesting visual image, but the visual appearance of the graphic will always be a "fun" state. Consciously create a visual reality in an unreasonable, illogical, impossible, non-existent reality in reality, resulting in a contrast between vision and reality. This kind of visual "reality" can drive the viewer's thinking vitality and generate psychological curiosity. People feel that this graphic creation is attractive and interesting, and then there will be an impulse to interpret. For example, a public service advertisement that successfully promotes smoking cessation. In visual terms, the first impression it gives is a column chart. Look closely and find that the "columns" in the picture are originally a cigarette of different lengths! Then 
look at the vertical the coordinates, in the same level as the complete cigarette, are written with the words "100 years old". This is the "finger of the finishing touch" of the whole picture, which lays a key point to be expressed in the picture. You don't need any words, you don't need any slogans, just this simple and simple picture, you have interpreted the designer's meaning to the fullest, leaving the audience with an endless aftertaste. At the same time, inadvertently, the advertisement is deeply imprinted in the hearts of the audience, which fully demonstrates the importance of fun to advertising $^{[4]}$. Figure 2 is an analysis of the use of public service advertisements for such graphic ideas.

\section{2 "Fun" in "form surprise"}

The term "form" is generally understood in art design as an external visual feature that is presented for a design purpose, including style, morphological structure, color, and expression techniques. The form focuses on artistic visual processing, pursuing new aesthetic concepts, and good visual processing not only has a certain form of aesthetics, but also helps to convey information. Formal expression requires certain aesthetic principles. The aesthetic principle is a concept of the public, and the design form should be expressed under this principle.

Visual elements are the elements that constitute the visual language. In the graphic design, the elements of the layout are the points, lines, planes and spaces that constitute the overall layout design. In order to well grasp the basic elements for the design of the visual language, must put the abstract concept of the element such as dot, line, face into a specific visual image, intuitive, and subjectively using point density, size, fangyuan, line thickness, and its merits and the various states, such as location and space, using beautiful and visual psychology, according to certain design principle, give full play to the characteristics of various forms and individual character, make a design with strong form aesthetic feeling.

"Formal Surprise" requires designers to effectively discover and create distinctive formal patterns while mastering the formal aesthetics, which raises new questions for designers. After an experienced designer has a graphic idea, he always tries various possibilities in the process of considering the best design form. In the case of many matchbox-sized areas, the creative collision of the form is created. At this time, the activity becomes a kind of joyful game, the form of the trial process becomes a fun game, the designer can follow the rules of the game, or can leave the rules of the game behind, to create a meaning, others feel strange visual effects. For example, consciously leaving a large area of white, placing a visual point on the off-center, causing a visual gap, forming a sense of interesting taste. Designers want to create visual "fun" to communicate their design intent more effectively ${ }^{[5]}$.

\section{Conclusions}

In general, the public service advertising graphic design is quite difficult and faces more challenges. In the graphic design of public service advertisements, we must have good creativity. The public service advertisements created should be interesting, attract the attention of the public, and use aesthetic ideas to infect the audience. In this way, we can continuously promote the development of public welfare undertakings and improve citizens' moral literacy. Therefore, it is necessary to make the advertisement interesting through graphic innovation and amazing visual form, so that people can pay attention to the advertisement and achieve the purpose of advertising. 


\section{Acknowledgement}

Liaoning social science planning fund project: Research on internet+Liaoning public service advertisement planning and communication strategy (L17BXW001).

\section{References}

[1] Yan Ge, Liu Zhongyu. Graphic Design Experience of Tobacco Control Public Service Advertisement[J]. Shenzhou Xun, 2015(10).

[2] Shen He. Application of Graphic Creativity in Graphic Design[J]. Design, 2017(7):48-49.

[3] Zhou Nanjiang. On the Application of Concrete Graphics in Public Service Advertising[J]. Artworks, 2016(3).

[4] Qin Yulv. Semiotic Analysis of Public Service Advertisements in Plane[J]. Youth, 2015(24).

[5] Gao Yun. On the Art Design Style of Plane Public Service Advertising[J]. China Press, 2012(6X):143-144. 